\title{
Task-Based Language Teaching. A new methodological approach to Second Language Acquisition - opportunities and challenges.
}

\author{
John O'Donoghue
}

\section{Zusammenfassung}

In den 1980er war auf dem Gebiet des Fremdsprachenerwerbs die Entwicklung des kommunikativen Ansatzes zu beobachten. In diesem Zusammenhang fand die Presentation-Practice-Production-Methode ihre Anwendung, die auf größere kommunikative Effektivität in der Zielsprache abzielte. Es bestehen jedoch Zweifel, ob die PresentationPractice-Production-Methode die gesetzten Ziele tatsächlich erfüllt hat. Aus dieser Kritik heraus entstand ein neuer didaktischer Ansatz, Task-Based Language Teaching, welcher den zentralen Fokus des Lernvorgangs auf die Aufgabenstellungen und deren Lösungen setzt. Gemäß dieser Theorie ist das Hauptziel des Spracherwerbs die Entwicklung der Fähigkeit, eine Vielzahl von Aufgabenstellungen in der Zielsprache zu meistern. Demzufolge sollen alle didaktischen Aktivitäten dieser Entwicklung dienen. Der vorliegende Beitrag befasst sich mit Task-Based Language Teaching und dessen Grundsätzen auf dem Hintergrund des effektiven Kommunikationsansatzes. Die neuen Rollen sowohl des Dozenten als auch des Lernenden werden hier definiert und die Herausforderungen dieser Methodologie für alle Beteiligten erläutert.
Abstract

In the 1980s in the area of Second Language Acquisition we saw the development of communicative approaches to language learning. This was led by the utilization of the Presentation-Practice-Production method, which aimed to enable learners to acquire greater communicative effectiveness in their target language. There have, however, been doubts raised about whether the Presentation-Practice-Production method effectively reaches its own goals. This has resulted in a new approach called Task-Based Language Teaching which sets the task at the centre of language learning. According to this theory the primary goal of language acquisition is the ability to deal with a wide variety of tasks in the target language. Everything that happens in the classroom should be directed at accomplishing this target. This paper seeks to present Task-Based Language Teaching and its principles in the context of communicate effectiveness, to define the new roles of both learner and teacher and to examine some of the challenges which this methodology presents to everyone involved in the learning process.

\section{Introduction to Task Based Language Teaching}

How teachers behave in the classroom, the material they present and the activities they ask their students to perform are all rooted in a theory of language and a theory of learning; in addition they assume certain objectives that language teaching should achieve. As teachers, do we believe that language is a system of rule-based governed structures which should be learnt by habit formation? Or do we view language as a system for expressing meaning which is best acquired in interaction and communication? Broadly speaking, Task-Based Language Teaching (TBLT) takes as its start- ing point the latter position, i.e. it has developed from a communicative theory of language.

TBLT derives some of its rationale from a distinction between »conscious learning « or »knowing that « and »subconscious acquisition« or »knowing how « (Nunan 2004: 77). What is the relationship between knowing a rule and applying that rule? Does the former necessarily precede the latter? And if so, does the former guarantee the latter? Teachers are familiar with the disparity between these processes; awareness of a rule and its successful application, i.e. between »learning « and »acquisition «. Nunan quotes Krashen's claim that »internalisation « of conscious learning does not, in fact, occur and that acquisition is a quite separate process from learn- 
ing. The view taken in this paper is that there is some connection between these processes which informs the version of TBLT adopted here. By allocating most classroom time to opportunities to acquire language and defining success in terms of communicative competence, TBLT clearly recognises the primacy of learners acquiring a language rather than merely learning it.

Teachers and learners are familiar with conventional textbooks that treat grammatical items in a singular, isolated manner. Having transmitted a particular item once to students we are surprised when it has largely been forgotten later. TBLT adopts a more »analytical « rather than "synthetic « approach (Nunan 2004: 11) in accommodating a less even, less linear process of language learning. If we accept the inherent instability of the learning process, the principle of recycling considered with the seven principles of TBLT below plays a particularly important role.

As we will see in the progress of this paper, the apparent dichotomy between the theories of »learning « and "acquisition « becomes less clear in teaching practice. What is the common ground between a structural approach focusing on usage and communicative language teaching's emphasis on use? How much structure is necessary to communicate successfully? Assuming that structure has an important role to play, when in the teaching cycle should it be taught? What is the difference between the structured language taught in TaskBased Language Teaching and its predecessor Presentation-Practice-Production? The different responses to these questions have, on the one hand, led to a "pure interpretation of TBLT and, on the other hand, to one that takes account of learners' needs for more guidance and direction (Littlewood 1981).

These varying responses relate directly to the roles of teacher and learner, which will be dealt with in greater detail below. TBLT endorses the principle of freedom by empowering the learners to determine much of what takes place in class and eschews, or at least redefines, the principle of teacher control. Later in this essay we shall analyse the problems that this shift of control may lead to.

\section{Task-Based Language Teaching}

In order to distinguish task-based teaching from other forms of teaching it is necessary to describe some of its leading characteristics. Skehan (1998: 95) provides us with five defining traits which may serve to clarify the nature of task. They are as follows: firstly, that meaning is primary; secondly, that learners are not given other people's meaning to regurgitate; thirdly, that some sort of relationship to comparable real-world activities should be present; fourthly, that task completion has some priority; and fifthly, that task assessment is in terms of outcome.

These traits differentiate TBLT from other approaches to language teaching in that the task - »real-world « or not - which is simulated demands a non-linguistic result, some impact on a real situation. It is more important to convey a message rather than demonstrate linguistic accuracy (Ellis 2003: 112) This shifts the focus of the learner's energies to attaining this result rather than merely employing lexico-grammatical items for their own sake, often referred to as »mastery«. The successful conclusion of the task should be the major criterion on which success is measured. Although, as Ellis points out, »the actual outcome of the task may be of no real pedagogic importance", rather it is »the cognitive and linguistic processes involved in reaching the outcome that matter (Ellis 2003: 8).

TBLT differs from other approaches such as the Audiolinguistic method in not prescribing the output that learners should perform. Although some element of controlled practice may be involved in the teaching cycle, as we shall see with the six-step procedure below, this is constructed as a stepping stone to freer self-determined expression at a later point. The function of the classroom is to enable learners to cope with tasks that they are likely to encounter beyond the classroom, language being treated as a tool with which learners can perform ordinary tasks.

All of the above traits are to some degree paradoxical in that they characterize an activity which is essentially designed to promote language acquisition. TBLT presupposes an imaginative leap on the part of all participants where the classroom becomes something else - anything from a post office to a boardroom. While some learners are willing to take this leap, others may be more reluctant to do so.

To facilitate this jump Nunan developed a Six-Step Procedure. Nunan's own definition of a task is that »a pedagogical task ... involves learners in comprehending, manipulating, producing or interacting in the target language while their attention is focused on mobilising their grammatical knowledge in order to express meaning«. (Nunan 2004: 4). His definition stipulates a 
sequence which enables learners to move from receptive to productive activities. Taking account of the fact that the classroom can at best approximate the real world and never completely replicate it, Nunan classifies real-world tasks simulated in the classroom as "pedagogical« ones, in so doing emphasising the essential nature of TBLT as a pedagogical endeavour. This pedagogical concept comprises six steps at the end of which the learners are equipped to accomplish the set task.

Step one: schema building. When confronted with new information we seek to cognitively process it by referring to old information, using the known as the basis for absorbing the unknown. Schemata can be defined as "mental structures that organise their knowledge of the world which they draw on in interpreting texts' (Ellis 2003: 41). For example, students studying business administration possess a wealth of real-world working experience, whether it be working in a call centre or in an investment bank. In this first step this knowledge is accessed, focussing the attention of the students on the topic and the key vocabulary they require.

Step two: controlled practice. This may be a listening or reading exercise which lets the students practise vocabulary, structures and functions. The students are following a fairly narrow template at this early stage but may also be encouraged to elaborate on - »manipulate « - the structures which they are presented with.

Step three: authentic listening practice. The learners are now exposed to intensive listening practice which is linked to specific tasks, e. g. matching. This should reinforce the language from the preceding step. This step represents a shift from the manipulating mentioned above to a focus on the meaning of specific structures in a communicative setting. These structures may then be used at the end when engaging in the task.

Step four: focus on linguistic elements. Having practised a number of linguistic items in relatively controlled ways, the students' attention is now drawn to examine the language they have been using. Nunan sees this as a key difference to PPP. By delaying the analysis of language from step one in PPP to step four, the students should be able to see more clearly the connection between "communicative meaning and linguistic form « (Nunan 2004: 32). Since they have encountered language initially and essentially as a means of communication, learners may be curious as to how this communication was structured. This approach adopts an inductive rather than a deductive approach, or as elaborated above, an »analytical« rather than a »synthetic « approach. Language is first encountered as »chunks«, later analysed, and then reassembled at the end as new »chunks «.

Step five: provide freer practice. This is where the students are empowered to go beyond the material provided, for example in a role play. The less confident students are free to utilise the vocabulary and structures learnt in the first four steps, the more confident ones may be using expressions that they learned outside of the present classroom. This is seen as a phase of real development whereby learners move away from imitation to innovation. They begin to develop their own »interlanguage «, a language marked by many non-native speaker elements but which should grow into a more standard version of the target language. As we shall see later this growth is dependent not least on the self-awareness and level of ambition of the learners involved.

Step Six: introduce the pedagogical task. This is the culmination of the teaching sequence where the task is carried out. The criticism of those advocating a purer form of TBLT may be that there has been too much directed input by this point. »A task stops being communicative only if the choice of activity has been prompted by purely linguistic considerations « (Ellis 2003: 16). This may lead the learners to regurgitate what the teacher or material has transmitted. While this criticism may be valid for a small minority, in my experience few learners do, in fact, parrot what they have been presented with. This six-step procedure enables those who feel uncertain about their communicative performance to rehearse a variety of elements which in step six may be employed to ensure an adequate level of production.

\section{Teaching Context}

Many third-level students, even at the beginning of the twenty-first century, seem to have experienced a rather teacher-centred, structuralist, grammar-based, translation approach to language learning. The approach to language learning in many secondary schools is what Canale refers to as »knowledge-oriented «, emphasising »controlled drills and explanation of rules« (Canale 1983: 14). Canale describes a situation which many of my students have in turn described to me: large groups, short class periods, teachers who are not necessarily communicatively competent and classroom discipline issues.

Perhaps as a consequence, some students seem rather reluctant to participate actively in class and feel that 
their spoken English is less than adequate for the business world that awaits them. However, they are aware that on graduation they will be confronted with a variety of tasks in the business work environment. Therefore, they are quick to recognise the value of skill-oriented activities and often prioritise such activities during needs analysis sessions. TBLT therefore seems to be the tailormade solution for this learner profile, reflecting the students' own priority of effective communication over a concern with formal aspects of language production.

TBLT may therefore be regarded as the bridge between a somewhat under-confident learner at undergraduate level and the demands of corporate tasks that our graduates will need to meet two or three years from their present classroom situation. It seems that the sixstep procedure that Nunan outlines in his Task-Based Language Teaching is best suited to guide students from dependent to independent user of English, from approximately B1 level to B2 or even C1 levels as defined in the Common European Reference framework.

\section{Seven Principles for TBLT}

Nunan also provides us with seven principles for TBLT which theoretically support the six steps outlined above. These principles are discussed with brief refer-

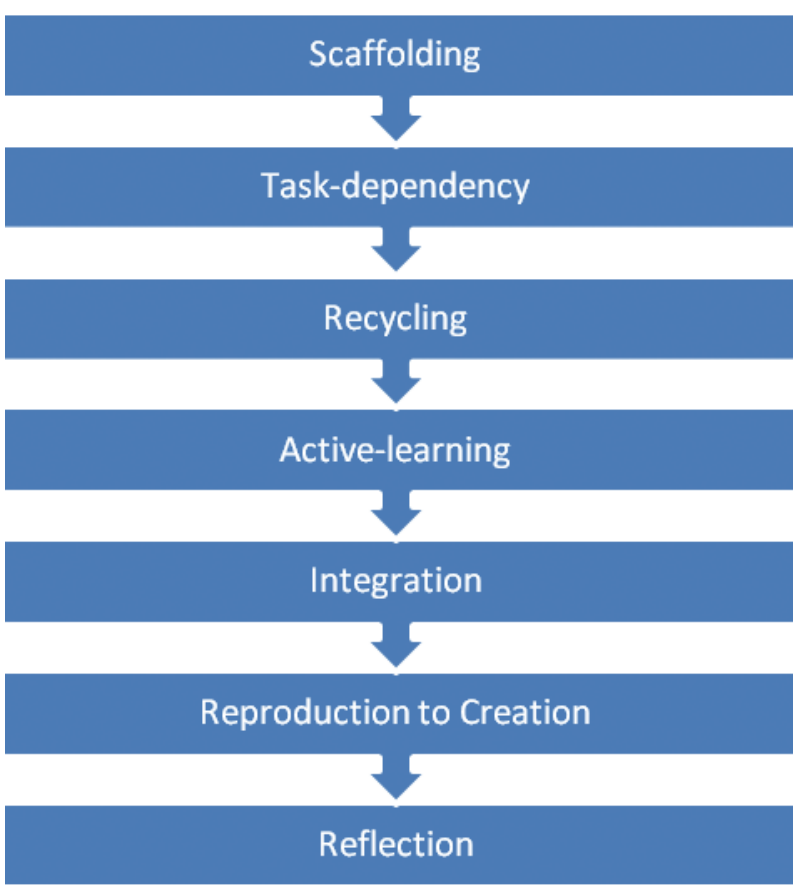

Fig. one: The seven principles of Task-based Language Teaching ence to a popular business English course book Market Leader Upper Intermediate. These principles may be illustrated as follows in figure 1.

Principle one: scaffolding. The classroom should "provide supporting frameworks« for the learners. Nunan does not expect learners to produce »what has not been introduced either explicitly or implicitly « (Nuna 2004: 35). The task in the course book Market Leader Upper Intermediate is processed and prepared in a variety of linguistic operations before it is presented as something familiar and feasible towards the end of the teaching cycle. For example, the unit which deals with finance opens with a number of discussion questions concerning personal borrowing. This activates a schema that relates to the general experience of dealing with money matters.

Principle two: task dependency. The tasks should be interlinked, ensuring that the learners grow from one task to the next. This parallels the development of »receptive-to-productive « whereby the learners first listen and read before proceeding to speaking and writing.

Principle three: recycling. As noted above, TBLT endorses an analytical approach to language learning. One of the demotivating aspects of language learning is the continual false application of lexico-grammatical items which have been frequently »learned « but obviously not »acquired «, e. g. omitting third person »s«, employing »if « and »would « in the same clause. Consequently, learners need to be able to experience key items and structures a number of times throughout an integrated cycle. In the Market Leader unit, key lexical items are integrated and repeated in listening, reading and comprehension tasks.

Principle four: active learning. This is the element of TBLT which many of my students find initially challenging and then enjoyable. TBLT focuses on the experience of the learner rather than that of the teacher (see below), i.e. acquisition by the learner rather than transmission by the teacher. The learners experience a high level of involvement which increases their motivation and arguably acquisition. The task is in this sense the crucible in which the various steps are brought together.

Principle five: integration. In more traditional forms of language teaching the linguistic forms are transmitted in »a static, atomistic and hierarchical« (Kohenen 1992) way, where little connection is made between the different forms that are available and what communicative effect they have. With this method semantic meaning is regarded as something absolute, inherent to 
the word itself, and static rather than as a flowing and negotiable element. By contrast, integration with Principle five means being aware of the connection between »the systematic relationships between form, function and meaning « (Nunan 2004: 37)

Principle six: reproduction to creation. This principle accommodates those learners who have few resources with which to initiate immediate communication, as may be demanded in a pure interpretation of TBLT. These learners are supplied with models which can be imitated and modified, providing the »scaffolding that can later be removed at the creative stage.

Principle seven: reflection. Although this seems to be missing from the six-step procedure it is an important element in shifting the learners' focus from grammatical minutiae to overall communicative competence. As students are often unsure of how they have performed in any given task, especially an unfocused one, it is important for the teacher to provide feedback, which is designed to trigger reflection, particularly in the area of communication effectiveness, i.e. considering the interpersonal as well as the transactional effect of the student's output. The students' major concern is expressed by such questions as »Did I do that properly? «In TBLT the teacher may reply »Did you perform the task effectively?«

\section{Communicative Effectiveness}

The main focus of classroom activity is often to facilitate learners to encode their own messages. Ellis refers to Yule's criticism of SLA researchers' concentration on this aspect as it is only one of three abilities comprising communicative effectiveness (Ellis 2003: 77). In Yule's model the perceptual and comparison abilities precede the linguistic ability and play an equally important role. According to this model, it is important that learners perceive the nature of the message that they are sending and how that message is received. These skills are »as much social and cognitive as they are linguistic « (ibid.). For students the linguistic challenge may seem paramount, and once they are in control of this means of communication they are then able to concentrate on negotiated solutions for tasks. In my experience students tend often to opt for a »selfcentred solution « (Ellis 2003: 78) where the students see problems from their own point of view rather than working on an »other-centred solution« where both perspectives (sender and receiver) are accounted for. One way to raise awareness of intersubjectivity is in the feedback stage where problems or breakdowns in the task are treated not as linguistic problems but issues of information processing and the perception of self and others.

\section{Task Difficulty: Learner, Task and Input.}

As may be apparent from the preference for the step approach outlined above, it seems reasonable to introduce tasks in a graded fashion for those learners who have experienced a more synthetic mode of language instruction. Grading tasks consists of taking account of three interconnected variables; learner factors, task factors and text/input factors (Brindly 1987).

One assumption underlying TBLT is that learners have a variety of resources at their disposal independent of both their immediate learning environment and their present teacher. The learner may possess prior knowledge of the topic that the task requires, be familiar with the task in his/her native language, have previous experience of TBLT, have the necessary linguistic abilities and confidence and be motivated to carry out the task. Some students may have been exposed to more communicative teaching approaches and are eager to engage with tasks in a communicative way. These students tend to have both the linguistic background and a more extrovert personality. Such students perceive the advantages of TBLT. This, however, normally applies to a minority of students. Many students do not possess such experience and may regard TBLT as unstructured and undermining. Therefore they require a sequence of mini-tasks to enlarge their »comfort zone« in a non-threatening way.

An example of how such learners can be led along this curve is by applying a gradation that distinguishes between »static «, »dynamic « and »abstract « tasks. Such tasks range from input which is constant (identifying lexis), to ones that change (role play) and finally ones that require some use of abstract thought (debate/discussion). This gradation may be paralleled by changing the form of group interaction; from pair-work to larger groups and then to discussions involving the whole class. Sequencing such tasks in this way may help to reduce inhibitions and levels of anxiety among learners. 


\section{Roles of Learner and Teacher}

In the TBLT approach the learner is empowered to use his/her own resources to navigate through a task and to utilise vocabulary and grammar acquired beyond the confines of the classroom. The learner is regarded as a resource of knowledge, abilities and talents in his/ her own right for whom the classroom is the opportunity to develop those resources to emerge equipped to deal with the linguistic challenges inherent in real-life situations. In this sense, the teacher simultaneously looks back on participants' experiences, integrating them into the acquisition process, and looks forward to their future experiences in an anticipative fashion. The teacher opens the classroom door to the wealth of experience that learners possess and seeks to equip them for real-world experience which he or she, however, may not be able to accurately predict. In my classroom situation students often enrich the task by contributing background information from their own corporate experience, e. g. negotiating a wage increase or settling a dispute. The advantage of TBLT is that it facilitates this input which in turn increases the identification of the students with their own learning.

In the same way that TBLT accommodates such experiences it also tries to prepare learners for future worklife experiences. It may be that the learner has a more accurate idea of what these activities will be than the teacher does. This non-linguistic competence confers greater control to the learner. Indeed, in a purer version of TBLT the participants would be free to design their own tasks. In my course on Job Applications, for example, students are free to select the company to which they intend to apply and anticipate - after some research - particular questions which that enterprise might pose in a job interview. This task encourages the learners to use their real-world knowledge to become more involved with the interview task preparation.

This shift in control obviously has implications for the role of the teacher. Breen and Candlin define this role as being that of »facilitator of the communication process, participant, observer and learner « (Breen/Candlin 1980). TBLT shifts the focus of control onto the leaner and his/her learning process. The conflict which Breen and Candlin observed is one which I have also experienced in the classroom. Students in my courses tend to expect clear instructions and some "modelling " of the language, and even clear criteria regarding the outcome of a task, »Did I do it correctly?« One potential disadvantage in the application of TBLT is that it regards this question as secondary. This may clash with learners' expectations concerning language-learning goals. Consequently, it may be bewildering for students if the teacher completely abdicates this traditional role and the six-step approach outlined above seems to bridge both roles, on the one hand reassuring those expecting the teacher to be a clear authority figure while at the same time guiding them into becoming successful users of English who can cope with both the »unpredictable« and »uncomfortable«.

\section{TBLT and its Challenges.}

What actually happens when students are engaged in a task? One can observe many cognitive and affective processes at work. Of course, the students have to understand the task but of equal importance are the affective processes. Students form groups, share information and insights, help each other and organise themselves. For my students, who may well have just arrived from a conventional academic lecture, this redirection of attention onto fellow students with its attendant social interaction often has a motivating effect.

In many communicative tasks listening possesses an interactive element as the students need to react directly to utterances made by the other party. Checking for understanding and negotiating for meaning become important tools at this stage. Breakdowns in communication or confusion mean that the negotiators have to be able to rephrase content, "No, I didn't mean that, I meant ...«. In my own experience intervention by the teacher does sometimes seem justified to help students rephrase their own content, enabling other students to comprehend others' output. This has a two-fold function: to help students recast their utterances and to facilitate other students' comprehension. When students repeat a task one can observe that conscious »noticing « (Schmidt 1990) has actually improved communicative performance. This »interventionist« approach can also occur in the post-task phase to avoid focusing too much attention on form during the task itself. Sometimes, however, one or two lexico-grammatical pieces of advice can help refocus attention on meaning. This is a decision which depends on the students' tolerance of their own frequency of mistakes, i.e. if the student feels undermined by his/her level of mistake, intervention may be helpful. If, on the other hand, the student 
is gaining fluency despite many inaccuracies, intervention may well be counterproductive and a more holistic approach may be called for. The post-task phase should comprise not merely of a list of mistakes but more importantly reinforces those scaffolding phrases from more competent learners which may help the less competent ones.

When performing the task for the first time, students often have difficulty estimating how successful their interaction will be. Therefore time is a significant factor, allowing students sufficient time to prepare and sometimes repeat the negotiation task or to perform a similar task has proved to increase effectiveness. Familiarity of information/topic is another factor influencing performance. In my Business Communication course the students are free to design and perform their own negotiation in the final weeks of the course. It is noticeable that students tend to choose material that matches their particular interests, e. g. computer science students often choose an IT topic on which to negotiate. In other words, to reduce the stress of a challenging task learners tend to choose familiar content and situations.

\section{Conclusion}

This paper has attempted to define what a task might be, to analyse how a specific procedure may be implemented, and to evaluate the benefits to learners and teachers and address some of the concerns students may have when encountering TBLT for the first time. TBLT can be implemented in a variety of ways and in my particular teaching context the six-step procedure outlined above seems a suitable bridge enabling learners who experienced more traditional approaches - which did not make them effective communicators of English - to develop »actual communication« skills from their »communication competence« (Canale 1983). In the future students may well experience more communicative teaching methods in school and therefore this procedure may well need to be refined or replaced by a more challenging interpretation of TBLT. This flexibility represents one of the many advantages of the TBLT approach.

\section{Bibliography}

Breen, M., Candlin C. (1980): The essentials of a communicative curriculum in language teaching. Language Learning, 1, 2, 89-112. Brindly, G. (1987): Factors affecting task difficulty. In: Nunan, D. (ed.): Guidelines for the Development of Curriculum Resources. National Curriculum Resource Centre, Adelaide.

Canale, M. (1983): »From Communicative competence to communicative language pedagogy«. In: Richards, K., Schmidt R. (eds.): Language and Communication, Longman.

Cotton, D., Falvey, D., Kent, S. (2001): Market Leader Upper Intermediate Business English. Pearson Education, Essex.

Ellis, R. (2003): Task-Based Language Learning and Teaching. Oxford University Press, Oxford.

Littlewood, W. (1981): Communicative Language Teaching: an introduction. Cambridge University Press, Cambridge.

Nunan, D. (2004): Task-Based Language Teaching. Cambridge University Press, Cambridge.

Skehan, P. (1998): A Cognitive Approach to Language Learning. Oxford University Press, Oxford.

Schmidt, R. (1990): »The role of consciousness in second language learning ${ }$. Applied Linguistics 11: 129-58.

\section{Author}

John O'Donoghue, MA

Fachbereich Betriebswirtschaft/Wirtschaftsinformatik

Technische Hochschule Wildau [FH]

$\mathrm{T}+493375$ 508-363

john.odonoghue@th-wildau.de 
